Canadian Oncology

Nursing Journal

Revue canadienne

de soins infirmiers

en oncologie

Volume 31, Issue 1 • Winter 2021

elSSN: 2368-8076 


\title{
Writing between the lines: A secondary analysis of unsolicited narratives from cancer survivors regarding their fear of cancer recurrence
}

\author{
by Jacqueline Galica, Stephanie Saunders, Kristen Haase, and Christine Maheu
}

\begin{abstract}
Background: Fear of cancer recurrence (FCR) is a common concern for posttreatment cancer survivors. In this secondary analysis we explore cancer survivors' unsolicited narratives on a survey about FCR.
\end{abstract}

Methods: We used an interpretive descriptive approach and statistical analyses to explore these narratives and determine the characteristics of survivors who did and did not provide narratives.

Findings: We developed three themes based on our analysis: describe posttreatment experiences; elaborate or contextualize FCR responses and use their voice toward change in cancer care. Those who provided narratives had lower overall FCR. Most narratives were used to provide context to responses or to indicate that some survey items were irrelevant.

Conclusion: Our results highlight potential reasons for unsolicited narratives on a survey and illuminate the potential value of expressive interventions for cancer survivors. Results indicate the usefulness of mixed methods approaches where survey respondents are offered space to provide open text.

Keywords: cancer survivors, fear, narration, surveys and questionnaires, qualitative research

$+\mathrm{H}$ ear of cancer recurrence (FCR), defined as "the fear, worry, - or concern relating to the possibility that cancer will come back or progress" (Lebel, Ozakinci, et al., 2016), affects as many as $72 \%$ of cancer survivors (Costa et al., 2016). Although some degree of FCR reflects a normal response to cancer

\section{AUTHOR NOTES}

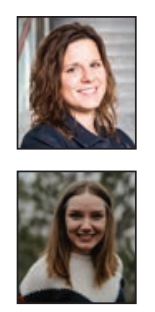

Jacqueline Galica, RN, PhD, CON(C); Assistant Professor, School of Nursing, Queen's University; Full Member, Division of Cancer Care \& Epidemiology, Queen's Cancer Research Institute; jacqueline.galica@queensu.ca

Stephanie Saunders, BNSc Student; School of Nursing, Queen's University; sms21@queensu.ca

Kristen Haase, RN, PhD; Assistant Professor, School of Nursing, University of British Columbia; kristenrhaase@ubc.ca

Christine Maheu, RN, PhD; Associate Professor, Ingram School of Nursing, McGill University; christine.maheu@mcgill.ca
(Lebel, Ozakinci, et al., 2016), the FCR experienced by some cancer survivors can have a great negative impact on their psychological well-being. Indeed, higher FCR has been associated with greater distress (Hall et al., 2019; Mehnert et al., 2013) and anxiety (Eyrenci \& Sertel Berk, 2018; Simard \& Savard, 2009), and poorer quality of life (Lebel, Simard, et al., 2016; Liu et al., 2017; Simard \& Savard, 2009). Furthermore, higher FCR is associated with greater use of health care resources (Lebel et al., 2013) and greater maladaptive behaviour changes (Hall et al., 2019), which may suggest that FCR interferes with survivors' ability to cope with cancer. Collectively, these findings illuminate the importance of exploring the FCR experienced by cancer survivors who have completed treatment for cancer.

In 2015, the primary author (JG) led a cross-sectional mixed-mode survey study designed to examine the predictors and mediators of FCR (Galica et al., 2019). The battery of surveys included valid and reliable measures (see Table 1) that were completed by 1,002 heterogeneous cancer survivors. Participants were recruited from a cancer survivorship clinic that followed patients for five years before discharge back to their primary care provider. Clinical data (e.g., diagnosis and treatment-related information) was extracted from clinic charts by the primary author (JG). As the surveys were returned, the research team noted that some participants included unsolicited narratives in the margins of their completed surveys, between survey items, or as handwritten or typed letters that accompanied completed surveys. These narratives were comprised of short sentences, paragraphs that spanned one or more margins, and/or letters included on additional sheets of paper. The research team wondered about participants' reasons for providing these narratives and, given that the narratives were not analyzed as part of the survey study, they were entered and stored in a database that was retained for this secondary analysis.

Few studies have addressed the unsolicited narratives received in survey research (Clayton et al., 1999; Maliski \& Litwin, 2007; Marshall et al., 2019; Warms et al., 2005), which may provide an additional understanding of participants' experiences (Clayton et al., 1999; Maliski \& Litwin, 2007; Warms et al., 2005). Unsolicited narratives have been described as written accounts of the narrator's experiences without investigation by the researcher (Frid et al., 2000). In this regard, survey study participants may provide unsolicited narratives as a dialogue with researchers (Warms et al., 2005), or to explain, elaborate and contextualize responses (Maliski \& Litwin, 2007) that survey items may fail to address (Marshall et al., 2019). Indeed, 
Table 1. Surveys completed by participants in the primary study

\begin{tabular}{|l|l|c|}
\hline Variable & Measure & $\mathbf{N}(\%)$ of Narratives (n=124) \\
\hline Socio-Demographics & Demographic Form (created by researchers for the primary study) & $12(9.7 \%)$ \\
\hline Fear of Cancer Recurrence & Fear of Cancer Recurrence Inventory (FCRI) (Simard \& Savard, 2009) & $58(46.8 \%)$ \\
\hline Self-Esteem & Rosenberg Self-Esteem Scale (RSES) (Rosenberg, 1965) & $2(1.6 \%)$ \\
\hline Optimism-Pessimism & Revised Life Orientation Test (LOT-R) (Scheier \& Carver, 1985) (0.0\%) & $24(19.4 \%)$ \\
\hline Illness Representation & Revised Illness Perception Questionnaire (IPQ-R) (Moss-Morris et al., 2002) & $2(1.6 \%)$ \\
\hline Personality & 10 -item Big Five Inventory (BFI-10) (Rammstedt \& John, 2007) & $8(6.5 \%)$ \\
\hline $\begin{array}{l}\text { Coping Styles and Strategies } \\
\text { 2 There were 18 (14.5\%) narratives that were written on separate documents (e.g., letters or post-it notes) and included with the surveys } \\
\text { that were returned to the researcher }\end{array}$ \\
\hline
\end{tabular}

written narratives provide an important source of data that recollects personal illness accounts (O'Brien \& Clark, 2010) that may not be captured by other research methods.

Given that unsolicited narratives can be useful to further understand the experiences of those who provided the narratives (Maliski \& Litwin, 2007) and be useful for cancer patients and survivors to cope with their illness (Carlick \& Biley, 2004), our team explored the unsolicited narratives of cancer survivors who completed a survey study about FCR in light of three objectives: 1) To explore cancer survivors' rationale for providing unsolicited narratives on a battery of surveys; 2) To determine the characteristics of participants who provided unsolicited narratives; and 3) To ascertain if differences existed between the demographic and clinical variables and level of FCR between those who provided narratives to those who did not.

\section{METHODS}

For this secondary analysis, we used multiple research methods (Hunter \& Brewer, 2016) to address the research objectives. All participants provided informed consent in the primary study (Galica et al., 2019). The Health Sciences Research Ethics Board at Queen's University provided ethical approval for this secondary analysis (\#6026530).

\section{Qualitative}

For the qualitative component (Objective 1), we used an interpretive descriptive method (Thorne, 2013, 2016) to analyze the unsolicited narratives received anywhere among the battery of surveys. Interpretive description is a qualitative approach that encourages researchers to move beyond traditional methods and integrate their disciplinary knowledge into the research process. This approach grounds the data in a clinically relevant context that contributes to informing and understanding nursing phenomena (Thorne, 2016). Two researchers (JG, SS) engaged in independent line-by-line coding of the unsolicited narratives using Microsoft Word and Microsoft Excel. As the analyses evolved, two researchers (JG, SS) placed the codes into subthemes and further arranged them into developing themes forming an initial

\begin{tabular}{|l|l|}
\hline \multicolumn{2}{|l|}{ Table 2. Strategies toward qualitative rigor } \\
\hline Principle & Strategies Used \\
\hline $\begin{array}{l}\text { Epistemological } \\
\text { integrity }\end{array}$ & - Design congruent with research objectives \\
\hline Credibility & $\begin{array}{l}\text { - Independent coding and theme development } \\
\text { by 2+ research team members } \\
\text { - Codes and themes reflect perspectives of } \\
\text { multiple participants }\end{array}$ \\
\hline Analytic logic & - Audit trail of key decisions \\
\hline $\begin{array}{l}\text { Interpretive } \\
\text { authority }\end{array}$ & $\begin{array}{l}\text { - Use of exemplary quotations } \\
\text { - Range of participants reflected in exemplars }\end{array}$ \\
\hline
\end{tabular}

framework through an iterative process. Code placement and theme disagreements were resolved with guidance from a third researcher (CM). The framework evolved throughout the analysis process and in consultation with the authorship team $(\mathrm{KH}, \mathrm{CM})$.

To ensure rigor in the qualitative component, Thorne's (2016) principles for creditability were used throughout the research process. These include epistemological integrity, credibility, analytic logic, and interpretive authority (Thorne, 2016). Thorne's (2016) considerations and strategies taken to achieve these are indicated in Table 2.

\section{Quantitative}

The quantitative component involved a statistical exploration of primary study data for the 47 participants who provided unsolicited narratives anywhere on the battery of surveys used in the primary study (Objective 2). To do this, SPSS version 25 was used to descriptively examine demographic and clinical variables (see Tables 3 and 4 for details), as well as level of FCR (see below) among participants who provided unsolicited narratives. Thereafter, independent t-tests and chi-square tests were used to explore differences in demographic variables, clinical variables and level of FCR between those who did and did not provide narratives in the primary study (Objective 3). 
Table 3. Demographic Characteristics of the Groups

\begin{tabular}{|c|c|c|c|c|c|c|}
\hline Variable & $\bar{x}$ & SD & $\overline{\mathbf{x}}$ & SD & Test Statistic ${ }^{\mathrm{a}}$ & $p$ \\
\hline Age & $\mathbf{N}$ & $\%$ & $\mathbf{N}$ & $\%$ & & \\
\hline Gender & & & & & 0.19 & 0.66 \\
\hline Male & 8 & 17.0 & 140 & 14.7 & & \\
\hline Marital Status & & & & & 1.62 & 0.20 \\
\hline Married or common-law & 28 & 59.6 & 653 & 68.4 & & \\
\hline Yes & 34 & 72.3 & 701 & 73.4 & & \\
\hline No & 13 & 27.7 & 254 & 26.6 & & \\
\hline Dependent children & & & & & 0.76 & 0.38 \\
\hline Yes & 5 & 10.6 & 146 & 15.3 & & \\
\hline No & 42 & 89.4 & 809 & 84.7 & & \\
\hline Level of Education ${ }^{b}$ & & & & & 8.90 & $<0.01$ \\
\hline Up to some university & 11 & 23.4 & 435 & 45.5 & & \\
\hline Ancestry & & & & & 0.88 & 0.35 \\
\hline White/Caucasian & 39 & 83.0 & 734 & 77.1 & & \\
\hline All other ethnicities & 8 & 17.0 & 218 & 22.9 & & \\
\hline Born in Canada & & & & & 3.90 & 0.04 \\
\hline Yes & 33 & 70.2 & 529 & 55.6 & & \\
\hline No & 14 & 29.8 & 423 & 44.4 & & \\
\hline Geographical Location & & & & & $\mathrm{FE}=.11$ & 0.05 \\
\hline Urban & 47 & 100 & 897 & 93.9 & & \\
\hline Rural & 0 & 0 & 58 & 6.1 & & \\
\hline $\begin{array}{l}\text { Note. FE = Fisher's Exact Te } \\
t=\text { independent } t \text {-test. Some } \\
{ }^{a} x^{2}=\text { Pearson Chi-Square Test } \\
\text { to completion of high school } \\
\text { refers to the completion of } u\end{array}$ & $\begin{array}{l}\text { due to } \leq \\
\text { ncies ma } \\
\text { otherwis } \\
\text { munity/t } \\
\text { duate de }\end{array}$ & $\begin{array}{l}\text { ome cel } \\
\text { o colum } \\
\text { b Leve } \\
\text { lool or } \\
\text { tgradua }\end{array}$ & $\begin{array}{l}\text { act significa } \\
\text { ls due to } m \\
\text { lucation wa } \\
\text { undergradu } \\
\text { dies. }\end{array}$ & $\begin{array}{l}\text { ed.); } p=\mathrm{Si}_{\xi} \\
\text { ized as "Up } \\
\text { ity, and "U, }\end{array}$ & $\begin{array}{l}\text { ficance Level (2 } \\
\text { some universit } \\
\text { ersity graduate }\end{array}$ & $\begin{array}{l}\text { ); } \\
\text { ch refers } \\
\text { er, which }\end{array}$ \\
\hline
\end{tabular}


Table 4. Clinical Characteristics of the Groups

\begin{tabular}{|c|c|c|c|c|c|c|}
\hline Variable & \multicolumn{2}{|c|}{ Narrative Group $(n=47)$} & \multicolumn{2}{|c|}{ No Narrative Group $(n=955)$} & Test Statistic ${ }^{a}$ & $p$ \\
\hline Time (years) Since Diagnosis & 10.77 & 6.86 & 8.99 & 5.02 & $t=-1.75$ & 0.09 \\
\hline \multirow[t]{2}{*}{ Number of Comorbidities } & 1.26 & 1.36 & 0.79 & 0.94 & $t=-2.31$ & 0.03 \\
\hline & $\mathbf{N}$ & $\%$ & $\mathbf{N}$ & $\%$ & & \\
\hline Breast & 29 & 61.7 & 632 & 66.5 & & \\
\hline All other cancers & 18 & 38.3 & 319 & 33.5 & & \\
\hline AJCC Stage & & & & & 2.67 & 0.10 \\
\hline Yes & 21 & 44.7 & 529 & 56.1 & & \\
\hline No & 26 & 55.3 & 414 & 43.9 & & \\
\hline Radiation Therapy & & & & & 0.04 & 0.84 \\
\hline Yes & 31 & 66.0 & 609 & 64.5 & & \\
\hline No & 16 & 34.0 & 335 & 35.5 & & \\
\hline Other Treatment & & & & & 1.40 & 0.24 \\
\hline Yes & 26 & 55.3 & 602 & 63.8 & & \\
\hline Yes & 21 & 44.7 & 211 & 22.1 & & \\
\hline No & 26 & 55.3 & 744 & 77.9 & & \\
\hline Relationship to survivorship clinic & & & & & 3.29 & 0.07 \\
\hline Active follow-up & 29 & 61.7 & 704 & 73.7 & & \\
\hline Discharged & 18 & 38.3 & 251 & 26.3 & & \\
\hline Know someone with a recurrence & & & & & 2.60 & 0.11 \\
\hline Yes & 28 & 59.6 & 454 & 47.5 & & \\
\hline No/Don't Know & 19 & 40.4 & 501 & 52.5 & & \\
\hline Knowing someone w/recur affects FCR & & & & & 1.66 & 0.20 \\
\hline Yes & 8 & 17.0 & 242 & 25.3 & & \\
\hline No/Don't Know & 39 & 83.0 & 713 & 74.7 & & \\
\hline
\end{tabular}


Fear of Cancer Recurrence Inventory

In the primary study (Galica et al., 2019), the Fear of Cancer Recurrence Inventory (FCRI) (Simard \& Savard, 2009) was used to assess FCR. The FCRI is a valid and reliable measure to assess FCR (Lebel, Simard, et al., 2016; Simard \& Savard, 2009). Item responses are based on a 5-point Likert-like scale, where 0 indicates 'not at all or never' and 4 indicates 'a great deal or all the time', and are summed to obtain subscale and overall FCRI scores (Simard \& Savard, 2009). Researchers have examined optimal FCRI cut-off scores to identify survivors with a level of FCR that may benefit from professional intervention, commonly referred to as clinically significant FCR: Scores $\geq 13$ (Simard \& Savard, 2015) and $\geq 22$ (Fardell et al., 2018) on the FCRI-Severity subscale have been suggested, and both cut-off scores are reported herein.

\section{FINDINGS}

Participants $(n=47)$ provided 124 distinct narratives anywhere on the battery of surveys and the 58 unsolicited narratives written on the FCRI accounted for the most narratives written among the measures (see Table 1 for the list of measures and frequencies of narratives on each). The FCRI location where participants provided the greatest number of narratives ${ }^{1}$ was in the space above item 31 ("I call my doctor or other health professional") ( $n=6)$. These narratives clarified that the ensuing section or item did not apply to participants as exemplified in the following narrative: "I rarely think about it [possibility of recurrence] and none of the questions really apply to me."

\section{Qualitative}

Through our interpretive description, we developed three themes related to participants' potential rationale for providing unsolicited narratives on a survey about FCR: 1) to describe their postcancer treatment experiences; 2) to elaborate or contextualize their responses about FCR, and; 3) to use their voice toward change in cancer care.

\section{To Describe Their Post Cancer Treatment Experiences}

Narratives described the impact of cancer in participants' lives, the beliefs that participants have about cancer, as well as their perspectives about their cancer journey. These narratives seemed to address the personal stories that the survey format precluded, but which participants felt were important for the researchers to understand about their experiences. Collectively, these narratives comprise a story about the postcancer treatment journey experienced by survivors.

Narratives indicated polarizing views about the impact of cancer in participants' lives. Sometimes, these views resulted in debilitating emotions or distress as exemplified by one participant's narrative: "I am lucky that my new cancer is very treatable but I'm depressed as hell and have no one in my life who understands." These thoughts impacted the outward actions of

1 Other common locations for written narratives was below item I7 ("How long have you been thinking about the possibility of cancer recurrence?") ( $\mathrm{n}=5$ ), and between FCRI item I3 ("I believe that I am cured and that the cancer will not come back") and the associated response options $(n=4)$. survivors, such as disrupting their ability to set life goals, negatively affecting their relationships, or depriving themselves of opportunities they may have otherwise engaged in. However, some participants expressed circumstances in their lives that had greater focus than cancer. For example, those with caregiving responsibilities for younger family members seemed more concerned about potential for cancer recurrence or having a chronic condition that exists independent of cancer. One participant noted in a hand-written letter sent back with the survey and addressed to the research team: "The diabetes diagnosis had a much worse affect on me [than cancer] because I have a family history. ... I am preoccupied with the diabetes and hardly ever think of the cancer unless I'm going for a check-up".

Participants wrote about their beliefs about the cause of their cancer diagnosis or a potential recurrence: age and genetics were specifically identified as non-modifiable factors of concern, and one participant described her belief as "everyone has cancer cells in the body." Many participants described their concerns about the cancer treatment they received, either as a cause for the secondary effects they were experiencing, or as a possible cause for a cancer recurrence or another cancer diagnosis. One participant wrote, "I have concern about a related condition [to treatment]. I have heart failure due to damage from chemotherapy ... For the past 16 years I have been under [cardiac] treatment... The goal is to maintain heart function at a level that allows me to live a normal life with some limitations." A subset of participants had strong beliefs that their cancer was cured and that there was minimal possibility of recurrence.

In telling their stories of posttreatment, participants acknowledged their cancer experiences and how this affected their outlook in life. One participant described, "cancer has made me realize I only have a finite amount of life... For me it is important to live each day to the fullest, because before you know it, it's over." A subset of narratives also described an attitude of moving forward and beyond cancer. Thus, the narratives in this theme allowed participants to further describe their personal cancer experiences that did not seem to fit into the survey.

\section{To Elaborate or Contextualize Their Responses About FCR}

Participants' narratives provided context to their survey responses to questions about their fears about the possible return of cancer. These narratives bolster our understanding about the contextual factors around FCR and the temporal factors that seem to shape participants' experiences with FCR.

FCR was experienced on a spectrum of intensity and frequency where some participants rarely worried about cancer recurrence and others experienced intense FCR. Experiences that triggered FCR included taking hormonal treatment, attending medical appointments, or hearing or thinking about cancer. One participant wrote "one fear that I have that I cannot control is my yearly mammogram. ... One time when they had to redo the $x$-ray, I fainted. I woke up on the floor with a sheet covering me." Additionally, the experiences of family members influenced an individual's thoughts and feelings towards their own worry and fear of cancer. For example, one participant stated: "I don't worry at all about recurrence of breast cancer.... I do worry about ovarian cancer because it is usually detected too late, as in my sister's case." 
The narratives also outlined factors that were useful to alleviate FCR. Many participants identified the passing of time and positive or grateful attitudes; however, the most common methods to alleviate FCR were having a positive cancer treatment experience or engaging in strategies to cope with FCR. Coping strategies that were specifically identified included self-reassurance, relaxation exercises, calling a healthcare professional, or self-distraction, as indicated by one participant's narrative: "I keep myself as occupied as possible with almost everything except personal cancer thoughts." These narratives reflected factors that contextualized and further described their FCR.

\section{To Use Their Voice Toward Change in Cancer Care}

Completing a survey related to FCR led participants to reflect on their positive and negative interactions within the cancer system and writing narratives was a way for them to voice their desire for changes to the system. The unsolicited narratives provided by participants seemed to provide a therapeutic outlet to speak about their cancer journey and to bolster the context for their responses. However, the notion that participants shared their viewpoints on this survey may demonstrate a functional gap in connecting participants with researchers and service organizations, so that they can make these contributions.

Some participants expressed thanks to the researchers for undertaking this study and a desire to contribute by participating in research, as stated by one participant, "I am extremely grateful for the high level of medical treatment I have received... I am pleased to add to the data in any way I can." This participant's narrative also reflected an element of altruism as a reason for participating in this study. Another participant reflected a similar sentiment for other patients not yet seen by cancer care providers: she states, "I was already in the system ... I had no prolonged wait to see a specialist. What about others?" Indeed, participants provided narratives about the challenges they experienced with accessing healthcare providers or a lack of coordinated care after cancer. One participant described how she took ownership toward managing her own care: "I do not feel a G.P. [general practitioner] can manage a former cancer patient. I feel I have to manage things myself - a bit scary." Other participants had strong preferences to receive follow-up care from oncology-specific providers, which was explained in part by participants' belief that their general practitioner lacked knowledge about how to best provide postcancer treatment survivorship care. In these narratives, participants seemed to want to share their perspectives and have them used as contributions toward changing the care offered to other cancer survivors.

\section{Quantitative}

Most participants who provided unsolicited narratives were women $(n=39 ; 83.0 \%)$ who were on average 66 years old (SD \pm 12.1, range 33-95 years), completed an undergraduate degree or higher ( $n=36 ; 76.6 \%$ ), and were diagnosed with breast cancer $(n=29 ; 61.7 \%)$ an average of $10.7(\mathrm{SD} \pm 6.8$, range $2-34)$ years previously. All participants lived in urban locations $(n=47$; $100 \%)$ and most were born in Canada $(n=33 ; 70.2 \%)$. Although few participants had a level of FCR that was categorized as clinically significant by an FCRI-Severity score cut-off of $\geq 22(n=7$, $14.9 \%$ ), nearly half of participants had a clinically significant FCR score when using the $\geq 13$ cut-off $(n=23,48.9 \%)$. Full participant details are provided in Tables 3, 4 and 5.

Table 5. Fear of Cancer Recurrence Among the Groups

\begin{tabular}{|c|c|c|c|c|c|c|}
\hline Variable & \multicolumn{2}{|c|}{ Narrative Group $(n=47)$} & \multicolumn{2}{|c|}{ No Narrative Group $\left(n=955^{\circ}\right)$} & Test Statistic & p \\
\hline \multirow[t]{2}{*}{ FCRI-Severity Subscale score } & 13.2 & 6.5 & 14.7 & 7.7 & $t=1.32$ & 0.18 \\
\hline & $\mathbf{N}$ & $\%$ & $\mathbf{N}$ & $\%$ & & \\
\hline Yes & 23 & 48.9 & 556 & 58.2 & & \\
\hline No & 24 & 51.1 & 399 & 41.8 & & \\
\hline Clinically Significant FCR $(\geq 22)^{c}$ & & & & & $x^{2}=1.03$ & 0.31 \\
\hline \multicolumn{7}{|c|}{$\begin{array}{l}\text { Note. FCR = Fear of Cancer Recurrence; FCRI = Fear of Cancer Recurrence Inventory; } p=\text { Significance Level ( } 2 \text {-Tailed); } \\
\mathrm{t}=\text { independent } \mathrm{t} \text {-test; } \chi 2=\text { Chi-square. Some frequencies may not sum to column totals due to missing data } \\
{ }^{a} \text { When using the } \geq 13 \text { cut-off score, one participant was missing sufficient data to calculate the FCRI scores, and when using the } \geq 22 \text { cut- } \\
\text { off score, two participants were missing sufficient data, resulting in } 953 \text { and } 954 \text { cases for these respective analyses. }{ }^{b} \text { FCRI cut-off score } \\
\text { per Simard and Savard (2015). }{ }^{c} \text { FCRI cut-off score per Fardell et al. (2018). }\end{array}$} \\
\hline
\end{tabular}


Differences Between Participants Who Provided Narratives to Those Without Narratives

Looking at the full sample of survey respondents from the primary study, those who provided narratives differed from those who did not provide narratives in their age, level of education attained and their location of birth. Compared to those without narratives, the narrative group was older $(\bar{X}=66.0$ vs $\bar{X}=60.9, p<.01$ ), had a higher proportion of participants who had completed an undergraduate degree or higher $\mathbf{( 7 6 . 6 \%}$ vs $54.5 \%, p<.01)$, and who were born in Canada $(70.2 \%$ vs $55.6 \%, p=.04)$. Regarding clinical characteristics, participants who provided unsolicited narratives had a greater number of co-morbidities $(\bar{X}=1.26$ vs $\bar{X}=0.79, p=.03)$. The no narrative group had a higher proportion of participants who did not have another primary diagnosis, recurrence or metastatic cancer in comparison to the group with narratives $(77.9 \%$ vs $55.3 \%, p<.01)$.

Participants who provided unsolicited narratives had lower overall FCRI scores $(\bar{X}=47.8$ vs $\bar{X}=58.3, p=.01)$. Neither of the dichotomized scores for clinically significant or not clinically significant levels of FCR differed between groups.

\section{DISCUSSION}

The findings from this study present our exploration into the nature and essence of unsolicited narratives on a survey about FCR. Cancer survivors' unsolicited narratives appear to be written as an opportunity to tell their story about their postcancer journey or to contextualize their FCR experiences. Furthermore, narratives indicated that cancer survivors intended for their voice to be used toward change in cancer care.

Notably, nearly half of survivors who provided narratives in this study had clinically elevated FCR according to the $\geq 13$ cutoff score (Simard \& Savard, 2015), which lies between proportions reported among other samples of heterogeneous cancer survivors (Lebel et al., 2013; Ng et al., 2019). The proportion of clinically elevated FCR in the current sample is interesting given that their mean time since diagnosis was more than 10 years earlier; however, systematic reviews report that FCR is stable over time (Crist \& Grunfeld, 2013; Simard et al., 2013). Instead, this finding may be explained by the large proportion of those who provided narratives identifying as women in that female gender is associated with higher FCR (Galica et al., 2019; Kelada et al., 2019; Ng et al., 2019). Results may also be explained by the finding that participants who provided narratives had a higher number of comorbidities which may serve as reminders of their cancer experience. Indeed, having a greater number of physical symptoms (Hall et al., 2019; Mehnert et al., 2013) and more reminders of cancer (Ziner et al., 2012) have been associated with higher FCR. Additionally, participants knew that the focus of the primary study was about FCR where the FCRI was presented second in the battery of measures to be completed. These points may have contributed to selection bias where more persons with higher FCR opted to participate in the primary study and/or prompted participants to focus and elaborate on their FCR beyond what the primary study measures permitted.
Indeed, given the quantitative survey approach of the primary study, participants were offered only a select number of response options to survey items (e.g., through a Likert scale). However, participants who provided unsolicited narratives wrote their narratives in empty spaces on the survey (e.g., in margins, between items, or as separate letters) suggesting that it is important to some survivors that they express their perspectives beyond what quantitative research designs permit. This point has implications for future research, such as for using mixed-method approaches, as it illuminates the importance for some cancer survivors to tell their story. In future studies, it would be useful to include open-text response options with each quantitative item and/ or engage in research projects that combine the benefits of both quantitative and qualitative methods.

The unsolicited narratives in the study seem to reflect a desire for participants to provide detail and context, thereby telling the researcher the story of their cancer experience. The beneficial impact of telling one's story, known as storytelling, has been recognized elsewhere (Chelf et al., 2000; Crogan et al., 2008). Storytelling is a process whereby one communicates important personal moments to others and involves reflection, creativity and accentuation of emotional components related to an event (Haigh \& Hardy, 2011). Storytelling or narrative-type interventions have been found to decrease clinical stress and depressed mood, as well as increase an individual's sense of peace (Crogan et al., 2008; Wise et al., 2018). In a health care system that emphasizes physical care, telling one's story may be a strategy for cancer survivors to reflect on and make sense of their emotions and experiences associated with cancer, or be an opportunity to facilitate connections with other cancer survivors (Laing et al., 2019). In relation to this understanding of storytelling, participants who wrote unsolicited narratives in the primary study may have felt the need to include short written segments to articulate their emotions, challenges and successes associated with their cancer experience inadvertently communicating their cancer journey.

Although storytelling can occur in other formats (e.g., digital (Lang et al., 2019)), the literature about writing-specific forums may be most relevant to this study's findings. Two writing forums that have been explored in cancer contexts include expressive writing, described as independent and unconstrained writing about personal experiences or life events (Pennebaker, 1997); and journaling, described as the sharing of thoughts, ideas, feelings and experiences through writing (Hayman et al., 2012). Although these forms of writing have demonstrated supportive qualities for people with cancer (Williams \& Jeanetta, 2016) and caregivers of people with cancer (Leung et al., 2019), the greatest benefits may be for people who have low levels of emotional support or who were recently diagnosed with cancer (Low et al., 2010). Notwithstanding these benefits, the focus (e.g., positive or negative) of the writing or journaling has been found to impact cancer patients' psychosocial outcomes (Low et al., 2010; Smith et al., 2005). 


\section{Study Limitations}

This study represents a secondary analysis of data, which may pose limitations because of the inability to clarify participants' intentions, meaning and purpose for writing their narratives (Thorne, 1998). Furthermore, the researchers were only able to read stand-alone narratives in the context and the location of where they were written on the survey leaving them only to infer an understanding about the relatedness of the narratives to the content of the measure or nearby items. Based on these limitations, results should be interpreted with caution and illuminate the need for further research in this area.

\section{Implications for Nursing Research and Practice}

In future survey research, it may be beneficial for nurse researchers to provide empty space for participants to leave notes about items that speak to them or to further articulate any thoughts that cannot be captured in responding to survey items. Indeed, other survey studies (Maliski \& Litwin, 2007; Marshall et al., 2019; Warms et al., 2005) found unsolicited narratives on or as letters returned with their completed surveys; however, in the age of increasing use of online surveys, providing such empty space around survey items may not be possible. Limited by platform designs, electronic surveys might hinder participants' ability to elaborate and provide context to questionnaire items when only Likert response options are offered. In such instances, it may be useful for nurse researchers to include optional open-ended questions or space to offer participants the flexibility to provide additional text as they desire. This space could be provided at intermittent points throughout the survey or after all survey questions are posed. Such recommendations are not limited to electronic surveys and could be applied to paper-based surveys and surveys administered as interviews.

In relation to nursing practice, study results encourage nurses to prompt patients to express their cancer experiences

\section{REFERENCES}

Carlick, A., \& Biley, F. C. (2004). Thoughts on the therapeutic use of narrative in the promotion of coping in cancer care. European Journal of Cancer Care, 13(4), 308-317.

Carver, C. S. (1997). You want to measure coping but your protocol's too long: Consider the Brief COPE. International Journal of Behavioral Medicine, 4(1), 91-100.

Chelf, J. H., Deshler, A. M. B., Hillman, S., \& Durazo-Arvizu, R. (2000). Storytelling: A strategy for living with and coping with cancer. Cancer Nursing, 23(1), 1-5.

Clayton, D. K., Rogers, S. N., \& Stuifbergen, A. (1999). Answers to Unasked Questions: Writing in the Margins. Research in Nursing Q Health, 22, 512-522.

Costa, D. S., Dieng, M., Cust, A. E., Butow, P. N., \& Kasparian, N. A. (2016). Psychometric properties of the Fear of Cancer Recurrence Inventory: An item response theory approach. Psychooncology, 25(7), 832-838. https://doi.org/10.1002/pon.4018

Crist, J. V., \& Grunfeld, E. A. (2013). Factors reported to influence fear of recurrence in cancer patients: A systematic review. Psychooncology, 22(5), 978-986. https://doi.org/10.1002/pon.3114

Crogan, N. L., Evans, B. C., \& Bendel, R. (2008). Storytelling intervention for patients with cancer: Part 2-Pilot testing. Oncol Nurs Forum, 35(2), 265-272. https://doi.org/10.1188/08. ONF.265-272 during and after cancer treatment. There are a variety of expressive methods that patients could use to suit their needs, such as verbal communication, journaling, and digital video-making. This telling of one's story can alleviate stress and anxiety; therefore, nurses could use storytelling as important psychosocial intervention by attentively listening to patients telling their experiences (Crogan et al., 2008).

\section{Conclusion}

This study provides unique insights into why survivors may provide unsolicited narratives on a survey about FCR and suggests which survivors may benefit from more expressive writing interventions to cope with FCR. Oncology nurses can incorporate expressive-type interventions into their clinical care and nurse researchers can provide space for survey respondents to qualify their responses to survey items (e.g., to provide justification, explanation, context, or emphasis).

\section{KEY POINTS}

- Possible rationale that cancer survivors provided unsolicited narratives on a survey about FCR were to describe posttreatment experiences; elaborate or contextualize FCR responses, and use their voice toward change in cancer care.

- Cancer survivors who may be more likely to leave unsolicited narratives on surveys include those with higher levels of education, born in Canada, and have lower overall FCR scores.

- Oncology nurses can use expressive-type interventions to promote cancer survivors to tell the story of their cancer experience.

\section{ACKNOWLEDGEMENTS}

The authors thank Weidong Kong for his statistical review of this manuscript.

Eyrenci, A., \& Sertel Berk, H. O. (2018). Validity and reliability of The Turkish Version of Fear of Cancer Recurrence Inventory. Turkish Journal of Oncology. https://doi.org/10.5505/tjo.2018.1759

Fardell, J. E., Jones, G., Smith, A. B., Lebel, S., Thewes, B., Costa, D., . . Butow, P. (2018). Exploring the screening capacity of the Fear of Cancer Recurrence Inventory-Short Form for clinical levels of fear of cancer recurrence. Psychooncology, 27(2), 492-499. https:// doi.org/10.1002/pon.4516

Frid, I., Ohlen, J., \& Bergbom, I. (2000). On the use of narratives in nursing research. Journal of Advanced Nursing, 32(3), 695-703.

Galica, J., Maheu, C., Brennenstuhl, S., Townsley, C., \& Metcalfe, K. (2019). Examining predictors of fear of cancer recurrence using Leventhal's Commonsense Model: Distinct implications for oncology nurses. Cancer Nursing. https://doi.org/10.1097/ NCC. 0000000000000760

Haigh, C., \& Hardy, P. (2011). Tell me a story--a conceptual exploration of storytelling in healthcare education. Nurse Educ Today, 31(4), 408-411. https://doi.org/10.1016/j.nedt.2010.08.001

Hall, D. L., Jimenez, R. B., Perez, G. K., Rabin, J., Quain, K., Yeh, G. Y., . . P Peppercorn, J. (2019). Fear of cancer recurrence: A model examination of physical symptoms, emotional distress, and health behavior change. Journal of Oncology Practice, 15(9), e787-e797. https://doi.org/10.1200/JOP.18.00787 
Hayman, B., Wilkes, L., \& Jackson, D. (2012). Journaling: Identification of challenges and reflection on strategies. Nurse Researcher, 19(3), 27-31.

Hunter, A., \& Brewer, J. D. (2016). Designing multimethod research. In S. N. Hesse-Biber \& R. Burke Johnson (Eds.), The Oxford Handbook of Multimethod and Mixed Methods Research Inquiry. https://doi.org/10.1093/oxfordhb/9780199933624.013.13

Kelada, L., Wakefield, C. E., Heathcote, L. C., Jaaniste, T., Signorelli, C., Fardell, J. E., . . . Cohn, R. J. (2019). Perceived cancer-related pain and fatigue, information needs, and fear of cancer recurrence among adult survivors of childhood cancer. Patient Education and Counseling, 102(12), 2270-2278. https://doi.org/10.1016/j. pec.2019.06.022

Laing, C. M., Moules, N. J., Sinclair, S., \& Estefan, A. (2019). Digital storytelling as a psychosocial tool for adult cancer survivors. Oncol Nurs Forum, 46(2), 147.

Lang, M., Laing, C., Moules, N., \& Estefan, A. (2019). Words, camera, music, action: A methodology of digital storytelling in a health care setting. International Journal of Qualitative Methods, 18, 160940691986324. https://doi.org/10.1177/1609406919863241

Lebel, S., Ozakinci, G., Humphris, G., Mutsaers, B., Thewes, B., Prins, J., . . . on behalf of the University of Ottawa Fear of Cancer Recurrence Colloquium attendees. (2016). From normal response to clinical problem: Definition and clinical features of fear of cancer recurrence. Support Care Cancer, 24(8), 3265-3268. https:// doi.org/10.1007/s00520-016-3272-5

Lebel, S., Simard, S., Harris, C., Feldstain, A., Beattie, S., McCallum, M., . . . Devins, G. M. (2016). Empirical validation of the English version of the Fear of Cancer Recurrence Inventory. Qual Life Res, 25(2), 311-321. https://doi.org/10.1007/s11136-015-1088-2

Lebel, S., Tomei, C., Feldstain, A., Beattie, S., \& McCallum, M. (2013). Does fear of cancer recurrence predict cancer survivors' health care use? Support Care Cancer, 21(3), 901-906. https://doi.org/10.1007/ s00520-012-1685-3

Leung, Y. W., Maslej, M. M., Ho, C., Razavi, S., Uy, P., Hosseini, M.-A., . . Peterkin, A. (2019). Cocreating meaning through expressive writing and reading for cancer caregivers. Journal of Palliative Care, 082585971987153. https://doi.org/10.1177/0825859719871538

Liu, J., Mahendran, R., Chua, S. M., Lam, K. F., Lim, H. A., Kuparasundram, S., . . . Griva, K. (2017). Validation of the English and Mandarin versions of the Fear of Cancer Recurrence Inventory in an Asian population. J Health Psychol, 1359105317727819. https:// doi.org/10.1177/1359105317727819

Low, C. A., Stanton, A. L., Bower, J. E., \& Gyllenhammer, L. (2010). A randomized controlled trial of emotionally expressive writing for women with metastatic breast cancer. Health Psychology, 29(4), 460-466. https://doi.org/10.1037/a0020153.supp

Maliski, S. L., \& Litwin, M. S. (2007). Unsolicited written comments: An untapped data source. Oncology Nursing Forum, 34(1), 142-147. https://doi.org/10.1188/07.ONF.142-147

Marshall, C., Linden, W., Ng, A., \& Vodermaier, A. (2019). In the margins: Unsolicited comments of cancer patients across the first year after diagnosis. Canadian Journal of Behavioural Science / Revue canadienne des sciences du comportement, 51(4), 261-268. https://doi.org/10.1037/cbs0000141

Mehnert, A., Koch, U., Sundermann, C., \& Dinkel, A. (2013). Predictors of fear of recurrence in patients one year after cancer rehabilitation: A prospective study. Acta Oncol, 52(6), 1102-1109. https://doi.org/10.3109/0284186X.2013.765063

Moss-Morris, R., Weinman, J., Petrie, K., Horne, R., Cameron, L., \& Buick, D. (2002). The Revised Illness Perception Questionnaire (IPQ-R). Psychology Q Health, 17(1), 1-16. https://doi. org/10.1080/08870440290001494
Ng, D. W. L., Kwong, A., Suen, D., Chan, M., Or, A., Ng, S. S., . . Lam, W. W. T. (2019). Fear of cancer recurrence among Chinese cancer survivors: Prevalence and associations with metacognition and neuroticism. Psychooncology, 28(6), 1243-1251. https://doi. org/10.1002/pon.5073

O'Brien, M. R., \& Clark, D. (2010). Use of unsolicited first-person written illness narratives in research: Systematic review. J Adv Nurs, 66(8), 1671-1682. https://doi.org/:10.1111/j.1365-2648.2010.05349.x

Pennebaker, J. W. (1997). Writing about emotional experiences as a therapeutic process. Psychological Science, 8(3), 162-166. https:// doi.org/10.1111/j.1467-9280.1997.tb00403.x

Rammstedt, B., \& John, O. P. (2007). Measuring personality in one minute or less: A 10-item short version of the Big Five Inventory in English and German. Journal of Research in Personality, 41(1), 203 212. https://doi.org/10.1016/j.jrp.2006.02.001

Rosenberg, M. (1965). Society and the adolescent self-image. Princeton, NJ: Princeton University Press.

Scheier, M. F., \& Carver, C. S. (1985). Optimism, coping, and health: assessment and implications of generalized outcome expectancies. Health Psychology 4(3), 219-247.

Simard, S., \& Savard, J. (2009). Fear of Cancer Recurrence Inventory: Development and initial validation of a multidimensional measure of fear of cancer recurrence. Support Care Cancer, 17, 241-251. https://doi.org/10.1007/s00520-008-0444-y

Simard, S., \& Savard, J. (2015). Screening and comorbidity of clinical levels of fear of cancer recurrence. Journal of Cancer Survivorship, 17(418), 1-23. https://doi.org/10.1007/s11764-015-0424-4

Simard, S., Thewes, B., Humphris, G., Dixon, M., Hayden, C., Mireskandari, S., \& Ozakinci, G. (2013). Fear of cancer recurrence in adult cancer survivors: A systematic review of quantitative studies. Journal of Cancer Survivorship, 7, 300-322. https://doi. org/10.1007/s11764-013-0272-z

Smith, S., Anderson-Hanley, C., Langrock, A., \& Compas, B. (2005). The effects of journaling for women with newly diagnosed breast cancer. Psycho-Oncology, 14(12), 1075-1082. The effects of journaling for women with newly diagnosed breast cancer. 10.1002/pon.912

Thorne, S. (1998). Ethical and representational issues in qualitative secondary analysis. Qualitative Health Research, 8(4), 547-555. The effects of journaling for women with newly diagnosed breast cancer. 10.1177/104973239800800408

Thorne, S. (2013). Interpretive description. In C. T. Beck (Ed.), Routledge International Handbook of Qualitative Nursing Research. Taylor \& Francis.

Thorne, S. (2016). Interpretive description: Qualitative research for applied practice (2nd ed.): Routledge.

Warms, C. A., Marshall, H. M., Hoffman, A. J., \& Tyler, E. J. (2005). There are a few things you did not ask about my pain: Writing on the margins of a survey questionnaire. Rehabilitation Nursing, $30(6)$.

Williams, F., \& Jeanetta, S. C. (2016). Lived experiences of breast cancer survivors after diagnosis, treatment and beyond: Qualitative study. Health Expectations, 19(3), 631-642. The effects of journaling for women with newly diagnosed breast cancer. 10.1111/hex.12372

Wise, M., Marchand, L. R., Roberts, L. J., \& Chih, M.-Y. (2018). Suffering in advanced cancer: A randomized control trial of a narrative intervention. Journal of Palliative Medicine, 21(2), 200207. The effects of journaling for women with newly diagnosed breast cancer. 10.1089/jpm.2017.0007

Ziner, K. W., Sledge, G., Bell, C. J., Johns, S. A., Miller, K. D., \& Champion, V. L. (2012). Predicting fear of breast cancer recurrence and self-efficacy in survivors by age at diagnosis. Oncol Nurs Forum, 39(3), 287-295. 